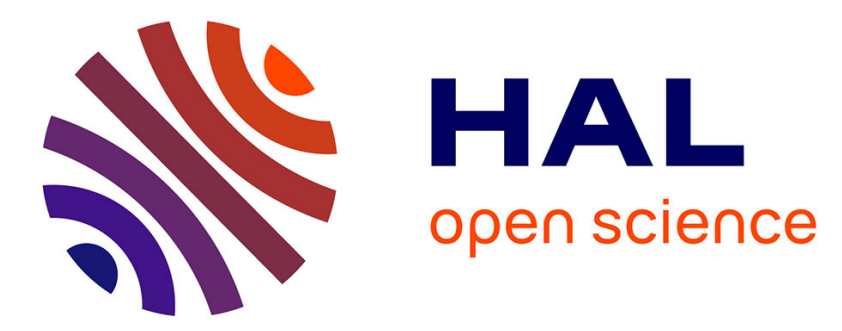

\title{
Molecular dynamics study of the hydration of lanthanum(III) and europium(III) including many-body effects
}

C. Clavaguéra, R. Pollet, J.-M. Soudan, V. Brenner, J.-P. Dognon

\section{- To cite this version:}

C. Clavaguéra, R. Pollet, J.-M. Soudan, V. Brenner, J.-P. Dognon. Molecular dynamics study of the hydration of lanthanum(III) and europium(III) including many-body effects. Journal of Physical Chemistry B, 2005, 109, pp.7616. 10.1021/jp051032h . hal-00081784

\section{HAL Id: hal-00081784 \\ https://hal.science/hal-00081784}

Submitted on 8 Sep 2006

HAL is a multi-disciplinary open access archive for the deposit and dissemination of scientific research documents, whether they are published or not. The documents may come from teaching and research institutions in France or abroad, or from public or private research centers.
L'archive ouverte pluridisciplinaire HAL, est destinée au dépôt et à la diffusion de documents scientifiques de niveau recherche, publiés ou non, émanant des établissements d'enseignement et de recherche français ou étrangers, des laboratoires publics ou privés. 


\title{
A molecular dynamics study of the hydration of
}

\section{lanthanum (III) and europium (III) including many-}

\section{body effects}

\author{
C. Clavaguéra, R. Pollet, J.M. Soudan, V. Brenner, J.P. Dognon*
}

Theoretical Chemistry Laboratory, DSM/DRECAM/SPAM-LFP (CEA-CNRS URA2453)

CEA/SACLAY, Bat.522, 91191 GIF SUR YVETTE, FRANCE

AUTHOR EMAIL ADDRESS: dognon@drecam.cea.fr

RECEIVED DATE (automatically inserted by publisher)

\begin{abstract}
Lanthanides complexes are widely used as contrast agents in magnetic resonance imaging (MRI), and are involved in many fields as organic synthesis, catalysis and nuclear waste management. The complexation of the ion by the solvent or an organic ligand and the resulting properties (for example the relaxivity in MRI) are mainly governed by the structure and dynamics of the coordination shells. All the MD approach already carried out for the lanthanide (III) hydration failed due to the lack of accurate representation of many-body effects. We present the first molecular dynamics simulation including these effects that account for the experimental results from a structural and dynamic (water exchange rate) point of view.
\end{abstract}

\section{MANUSCRIPT TEXT:}

The interest in Lanthanides (III) ions increased in many fields over the last decade. The main applications cover medical diagnosis (contrast agents in Magnetic Resonance Imaging, luminescent 
probes for protein), catalysis and organic synthesis, nuclear waste management. The study of the coordination of lanthanide (III) ions and the water exchange in aqueous solutions is of particular importance for the understanding of the chemical processes in which these ions are involved. A consensus started to emerge from experimental data in aqueous solution about the change of the coordination number from nine to eight along the series (see ref. 1 and references therein). At the gadolinium break (actually from $\mathrm{Sm}^{3+}$ to $\mathrm{Gd}^{3+}$ ), where the coordination number $(\mathrm{CN})$ is close to 8.5 , a maximum of the water-exchange rate is observed. ${ }^{1}$ There are not many experimental values and only with a limited precision. From a theoretical point of view and with respect to the experimental values, Floris and Tani obtained a constant $\mathrm{CN}$ of 9 and an opposite residence time behavior along the series. $^{2}$ They performed Molecular Dynamics (MD) simulations using periodic boundary conditions (PBC) and effective ion-water pair potentials based on ab initio calculations with polarizable continuum model. Merbach and coworkers ${ }^{3}$ succeeded in predicting the $\mathrm{CN}$ experimental trend by scaling the permanent dipole moment of a water molecule as a function of the ion-water distance to incorporate some polarization effects. Unfortunately, they obtained much shorter water residence times for the heavier lanthanides. These failures highlight the importance of many-body effects for highly charged ions in polar solvents as water. This could be easily understood from ab initio calculations on $\mathrm{Ln}^{3+}-\mathrm{H}_{2} \mathrm{O}$. The coordination energy partitioning method (CEP), ${ }^{4}$ derived from a modified reduced variational space method, allows us to estimate the energetic contribution of the polarization to the interaction energy: $63 \%$ for $\mathrm{La}^{3+}$ and $54 \%$ for $\mathrm{Eu}^{3+}$. $\mathrm{Ab}$ initio $\mathrm{MD}$, while attractive, cannot be used as mean residence times for the hydration of lanthanides are at least one order of magnitude larger than the possible simulation time (few ps). Moreover, classical MD simulations with high-level model potentials (for example taking into account polarization and backpolarization) can still remain too much computing time expensive if periodic boundary conditions are used.

We present here the first results obtained with a new approach based on a molecular dynamic simulation of an $\mathrm{Ln}^{3+}-\left(\mathrm{H}_{2} \mathrm{O}\right)_{60}$ cluster $\left(\mathrm{Ln}^{3+}=\mathrm{La}^{3+} \& \mathrm{Eu}^{3+}\right)$ with spherical boundary conditions and taking into account many-body effects. This work is based on the AMOEBA force field. ${ }^{5-7}$ The 
electrostatic model is built from atomic multipoles in contrast to conventional force fields that only include atomic partial charges. They are obtained from a Stone's distributed multipole analysis protocol through the GDMA program. ${ }^{8}$ Electronic many-body effects are described using a selfconsistent dipole polarization procedure. Repulsion-dispersion interactions between pairs of nonbonded atoms are represented by a buffered 14-7 potential. The AMOEBA parameters for the ions were obtained from ab initio calculations at MP2 level on several geometrical configurations of the "dimer" $\mathrm{Ln}^{3+}-\mathrm{H}_{2} \mathrm{O}$. All $1 \mathrm{~ns}$ MD simulations were carried out at $300 \mathrm{~K}$ with a $1 \mathrm{fs}$ time step.

The first peak position of the radial distribution function $\mathrm{g}(\mathrm{r})$ show the very good agreement obtained for the $\mathrm{Ln}^{3+}-\mathrm{O}$ distance with respect to the experimental data (Figure 1 and Table 1).

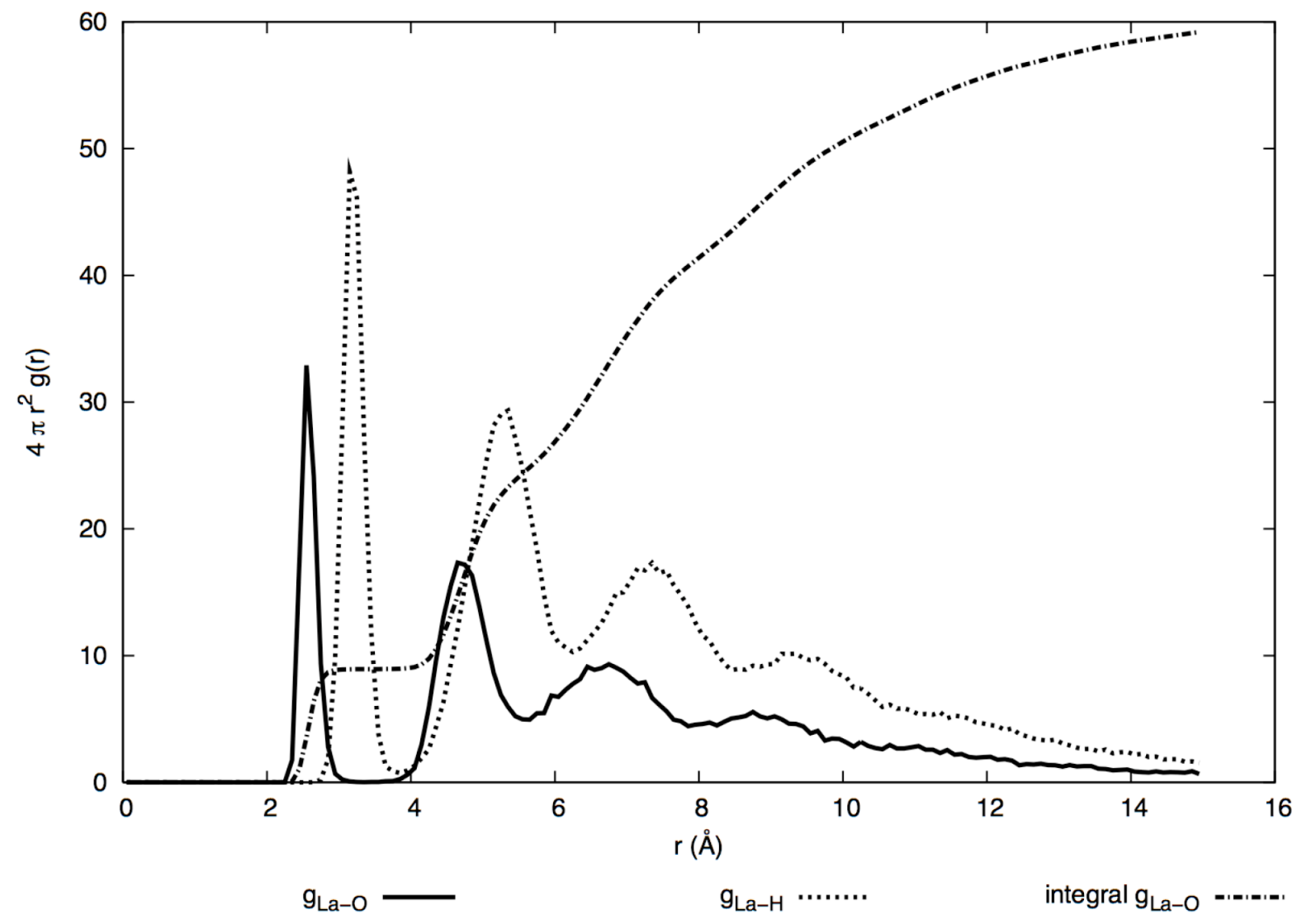

Figure 1: radial distribution function $(\mathrm{RDF}) \mathrm{g}_{\mathrm{La}-\mathrm{O}}(\mathrm{r}), \mathrm{g}_{\mathrm{La}-\mathrm{H}}(\mathrm{r})$ and integration curve for $\mathrm{La}^{3+}$ 


\begin{tabular}{|c|c|c|}
\hline & $\mathrm{La}^{3+}$ & $\mathrm{Eu}^{3+}$ \\
\hline Mean CN (1t shell) & $8.9(\approx 9.1)$ & $8.4(\approx 8.3)$ \\
\hline $\begin{array}{c}\mathrm{Ln}^{3+}-\mathrm{O} \text { distance } \\
\left(1^{\text {st }} \text { shell }\right)\end{array}$ & $2.56 \AA(\approx 2.54-2.58 \AA)$ & $2.44 \AA(\approx 2.43 \AA)$ \\
\hline $\mathrm{CN}=9$ & $91.6 \%$ & $36.8 \%$ \\
\hline $\mathrm{CN}=8$ & $7.7 \%$ & $63.2 \%$ \\
\hline $\mathrm{CN}=10$ & $0.7 \%$ & $0.0 \%$ \\
\hline $\mathrm{n} \mathrm{H}_{2} \mathrm{O}\left(2^{\text {nd }}\right.$ shell $)$ & 15.9 & 15.7 \\
\hline $\begin{array}{c}\mathrm{Ln}^{3+} \ldots \mathrm{O} \text { distance } \\
\left(2^{\mathrm{nd}} \text { shell }\right)\end{array}$ & $4.68 \AA(\approx 4.63 \AA)$ & $4.64 \AA$ \\
\hline $\begin{array}{l}\text { Residence time } \\
\qquad\left(1^{\text {st }} \text { shell }\right)\end{array}$ & $980 \mathrm{ps}$ & $300 \mathrm{ps}$ \\
\hline
\end{tabular}

Table 1: summary of theoretical results (with experimental data in parentheses)

Water dipoles in the first coordination shell are strongly radially oriented with a tilt angle (between the $\mathrm{HOH}$ bisector and the $\mathrm{O}-\mathrm{La}^{3+}$ axis) smaller than $20^{\circ}$ and nearly identical for the two cations.

With respect to the currently accepted experimental behavior in the first coordination shell, we obtained from the $\mathrm{g}(\mathrm{r})$ a decrease of the coordination number $(\mathrm{CN})$ from 8.9 for $\mathrm{La}^{3+}$ to 8.4 for $\mathrm{Eu}^{3+}$ (middle of the lanthanide series). The experimental data in Table 1 are from X-ray diffraction studies. ${ }^{9,10}$ More recent EXAFS studies are not useful to distinguish unambiguously between a CN of 8 or 9 for $\mathrm{Ln}^{3+}$ ions as concluded by the authors. ${ }^{11}$

A second coordination shell is clearly identified with about 16 water molecules. Experimental data for this shell are very scarce with large uncertainties. The number of water molecule in this shell is distributed over the range 13 to 20 because of deficiencies of the majority of the methods. ${ }^{12}$ The most reliable experimental data are obtained from Large Angle X-ray Scattering (LAXS) which gives 18 water molecules for $\mathrm{La}^{3+}$ and a bond distance $\mathrm{La}^{3+} \ldots \mathrm{O}$ of $4.63 \AA^{13}$ Our calculated results 
for $\mathrm{La}^{3+}$ are in very good agreements with this data (see Table 1). For $\mathrm{Eu}^{3+}$, there is no experimental data and we propose the values given in Table 1. Water dipoles in the second shell still remain strongly oriented by the ion. In the first and second shell, the ion-water interaction is much stronger than the water-water one as already observed for the hydration of some +2 ions (see ref. 14). It is only beyond the second shell that we observe a competition between these two types of interactions.

The coordination number is generally determined experimentally by the static structure of the first coordination shell. A dynamic analysis of the system (solvent exchange reactions, etc.) gives a more realistic picture of the ion hydration as pointed out by Impey et al.. ${ }^{15}$ They introduce the notion of persisting coordination which measures the average number of water molecules $n_{\text {ion }}(t)$ which remain longer than a time $t$ in a given hydration shell. This statistical approach gives much more quantitative information than a direct count of the exchange events. We have estimated the mean residence time of a water molecule in a shell fitting the time correlation function $n_{\text {ion }}(t)$ with a Weibull stretched exponential function. ${ }^{16}$

An analysis of the MD trajectories shows that an arrangement with $\mathrm{CN}=9$ is the most frequent for $\mathrm{La}^{3+}$, namely $\approx 92 \%$, whereas an equilibrium value between 9 and 8 is the preferred arrangement for $\mathrm{Eu}^{3+}(37 \%$ for $\mathrm{CN}=9$ and $63 \%$ for $\mathrm{CN}=8$ ). We note that an arrangement with $\mathrm{CN}=10$ is never obtained. So the water exchange mechanism must therefore be dissociative (an intermediate of reduced coordination number occurs during the solvent exchange reaction) for $\mathrm{La}^{3+}$ in agreement with the expectations of Helm and Merbach. ${ }^{17} \mathrm{For} \mathrm{Eu}^{3+}$, our MD simulation results make it possible to conclude to the coexistence of associative and dissociative pathways. The figure 2 shows the water migrationbetween first and second hydration shell. 


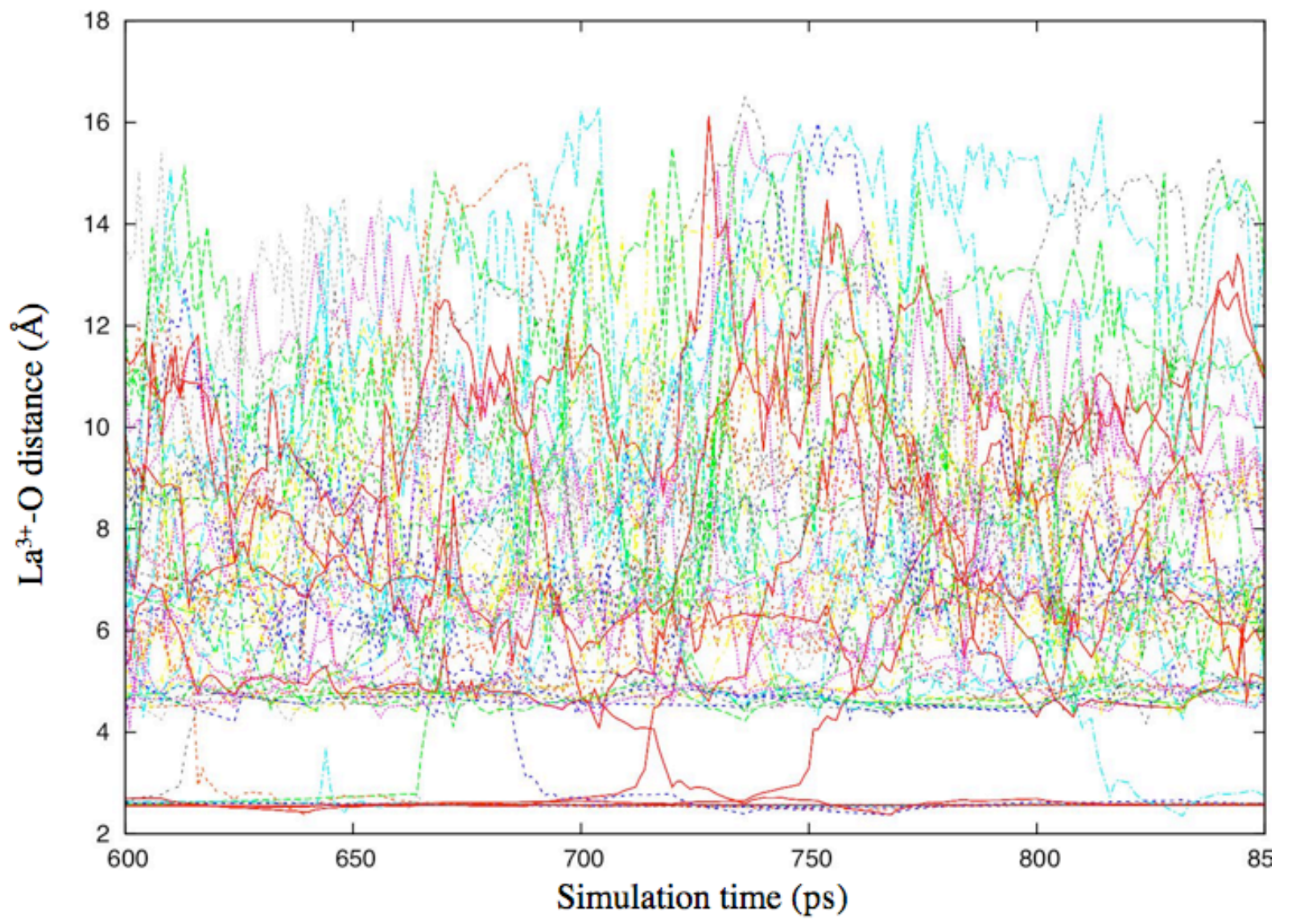

Figure 2: part of a MD trajectory $\left(\mathrm{La}^{3+}\right.$ hydration) after filtering with Daubechies $\mathrm{D}_{4}$ wavelets

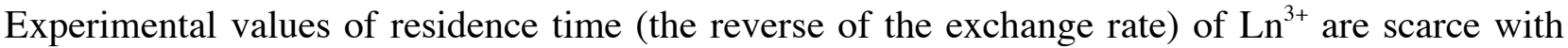
often large uncertainties. The most accurate experimental technique, namely ${ }^{17} \mathrm{O}-\mathrm{NMR}$ fails to analyze lighter lanthanides because very high field measurements should be needed. Only an upper bound of $2.5 \mathrm{~ns}$ is known for $\mathrm{Pr}^{3+},{ }^{1}$ while the value that should correspond to $\mathrm{La}^{3+}$ is expected to be longer. An alternative technique, namely ultrasonic absorption, yields a residence time of $4.8 \mathrm{~ns}$ for $\mathrm{La}^{3+}{ }^{18}$ There is no experimental value concerning $\mathrm{Eu}^{3+}$. We can suppose an order of magnitude close to NMR values obtained by Helm et al. for $\mathrm{Gd}^{3+}$ and $\mathrm{Eu}^{2+}$ (isoelectronic to $\mathrm{Gd}^{3+}$ ) i.e. ranging between 833 ps and 227 ps $(\mathrm{CN}=8) .{ }^{17}$ We obtain a 300 ps value for $\mathrm{Eu}^{3+}$ with a $\mathrm{CN}$ of 8.4 (Table 1).

With respect to the experimental uncertainties, our values are in good agreement with experimental data. It should be pointed out that only an explicit high-level treatment of polarization effect leads to agreement with experimental results. The values predicted if polarization is neglected, 
or if a simple model is used thereof, are in error by several orders of magnitude, particularly for the exchange rate.

It is the first time that a theoretical chemistry approach is able to simulate simultaneously the structure and dynamic of lanthanides (III) hydration shells. We have shown that MD simulations with an accurate polarizable force field and a cluster approach could be a valuable alternative without losing information in the description of this microscopic system.

ACKNOWLEDGMENTS: This work was supported by EMIL (European Molecular Imaging Laboratories) European Network of Excellence (Sixth Framework Programme) and the Department of Research on the Condensed State, Atoms and Molecules (DRECAM) of the CEA Physical Sciences Division (DSM).

\section{REFERENCES}

1. Helm, L.; Merbach, A. E. Coord. Chem. Rev. 1999, 187, 151-181.

2. Floris, F. M.; Tani, A. J. Chem. Phys. 2001, 115, 4750-4765.

3. Kowall, T.; Foglia, F.; Helm, L.; Merbach, A. E. J. Am. Chem. Soc. 1995, 117, 3790-3799.

4. Clavaguéra-Sarrio, C.; Hoyau, S.; Ismail, N.; Marsden, C. J. J. Phys. Chem. A 2003, 107, 45154525 .

5. Ren, P. Y.; Ponder, J. W. J. Comput. Chem. 2002, 23, 1497-1506.

6. Ren, P. Y.; Ponder, J. W. J. Phys. Chem. B 2003, 107, 5933-5947.

7. Grossfield, A.; Ren, P. Y.; Ponder, J. W. J. Am. Chem. Soc. 2003, 125, 15671-15682.

8. Stone, A. J. GDMA 1.3, University of Cambridge: England, 2003.

9. Habenschuss, A.; Spedding, F. H. J. Chem. Phys. 1979, 70, 3758-3763.

10. Habenschuss, A.; Spedding, F. H. J. Chem. Phys. 1980, 73, 442-450.

11. Allen, P. G.; Bucher, J. J.; Shuh, D. K.; Edelstein, N. M.; Craig, I. Inorg. Chem. 2000, 39, 595601.

12. Ohtaki, T.; Radnal, T. Chem. Rev. 1993, 93, 1157-1204.

13. Naslund, J.; Lindqvist-Reis, P.; Persson, I.; Sandstrom, M. Inorg. Chem. 2000, 39, 4006-4011. 
14. Clavaguéra-Sarrio, C.; Brenner, V.; Hoyau, S.; Marsden, C. J.; Millié, P.; Dognon, J. P. J. Phys. Chem. B 2003, 107, 3051-3060.

15. Impey, R. W.; Madden, P. A.; McDonald, I. R. J. Phys. Chem. 1983, 87, 5071-5083.

16. Weibull, W. J. Appl. Mech. 1951, 18, 293-297.

17. Helm, L.; Merbach, A. E. J. Chem. Soc., Dalton Trans. 2002, 633-641.

18. Fay, D. P.; Litchinsky, D.; Purdie, N. J. Phys. Chem. 1969, 73, 544-552. 